\title{
DESIGN AND DEVELOPMENT OF CONCRETES FOR SPECIAL REHABILITATION TASKS
}

\author{
Alexander Flohr ${ }^{1, *}$ and Andrea Osburg ${ }^{1}$ \\ ${ }^{1}$ Bauhaus-Universität Weimar, Faculty of Civil Engineering, F. A. Finger-Institute for Building Material Engineering, Chair of \\ Building Chemistry and Polymer Materials, Coudraystraße 11A, 99423 Weimar (Germany)
}

\begin{abstract}
The requirements for concrete restoration are not only aspects of retrofitting or restoration of bearing capacity but also aspects of preservation of historic structures, such as industrial monuments or civil engineering structures and buildings of the 1960s [1]. Thereby the facsimile replication of the concrete surface is a particular challenge. For the manufacture of delicate and complex structures with restricted accessibility self-compacting concrete (SCC) is well suited [2]. A modification with polymers normally ensures the durability of repair mortars or concretes (PCC) [3]. The combination of PCC and SCC to the Polymer-modified Self-Compacting Concrete (PSCC) for the restoration of historic concrete constructions is the logical consequence, to combine the advantages of both materials and is therefore an interesting alternative to well established materials and methods. Historic concrete constructions are often manufactured of concretes with very stiff consistencies, the so called tamped concretes. So there is a need to develop materials and methods for the rehabilitation of structures made of tamped concrete. For this reason, first investigations have been performed to the recipe development and optimization of its composition, but also properties, furthermore to the design possibilities and how polymers influence the concrete properties. In Germany between 1920 and 1970 industrial buildings and hydraulic structures have been built with concretes, where the content of Portland cement clinker was nearly complete substituted by latent hydraulic materials. The binders of those concretes contain large quantities of blast furnace slag and calcium sulphate and are called super-sulphated cement (SSC). Because of the high sulphate content, the compatibility of concrete structure with SSC is not given to concretes or mortars with other cements. If there is an adequate range of moisture, harmful new formations of phases will occur in the contact zone between SSC-concrete and the other concrete. In the field of rehabilitation PCC are well established. These are polymer-modified mortars or concretes with Portland cement, which are not suitable for the rehabilitation of structures of SSC-concrete. An alternative is the polymer-modification of SSC-concretes with polymers.
\end{abstract}

\section{Introduction}

Within the scope of the research project nuBau-Transfer "Methods for the development and application of innovative, functional materials for the restoration of buildings" different materials for repair and restoration of buildings have been developed and optimized. Presented in this paper are selected results of the development of Polymer-modified Self-Compacting Concrete, of tamped concrete and of Polymer-modified Super-Sulphated Cement Concrete.

\section{Polymer-modified Self-Compacting Concrete (PSCC)}

At first the studies focused in the development and application of a filler type PSCC with a polymer content of $10 \%$ of the cement weight. The PSCC mixture was projected and modified to achieve optimal material properties. To characterize the concrete as well as for comparative studies, fresh and hardened concrete properties were determined and compared to the properties of a not modified reference. The polymers in the structure of the hardened concrete reduced the elastic modulus and the compressive strength. A low elastic modulus and a moderate compressive strength are important for the functional efficiency of repair systems. The measured values for bonding strength were always higher than $2 \mathrm{~N} / \mathrm{mm}^{2}$ and the failure occurred in all cases in the substrate. Furthermore, the PSCC could be categorized as freeze-thaw resistant and resistant to freeze-thaw and de-icing salt. In contrast, the reference concrete is not resistant to freeze-thaw and de-icing salt. So it can be stated, that a polymer modification is necessary to guarantee the durability of this concrete. [4][5]

On the basis of these results further concrete formulations have been developed, which meet the current

* Corresponding author: alexander.flohr@uni-weimar.de 
requirements from practice. The methodological approach was based on successive investigations on paste, mortar and concrete. These tests formed the basis for a purposeful concrete design, also if there are variations of the precursors, which are necessary because of certain concrete technological boundary conditions. The rheological properties of the pastes, the base mortars and concretes have been determined using selected methods und compared to the results of the already established concrete compositions. Figures 1 to 6 exemplify the investigations on fresh mortar and fresh concrete. The desired characteristics have been unerringly achieved.

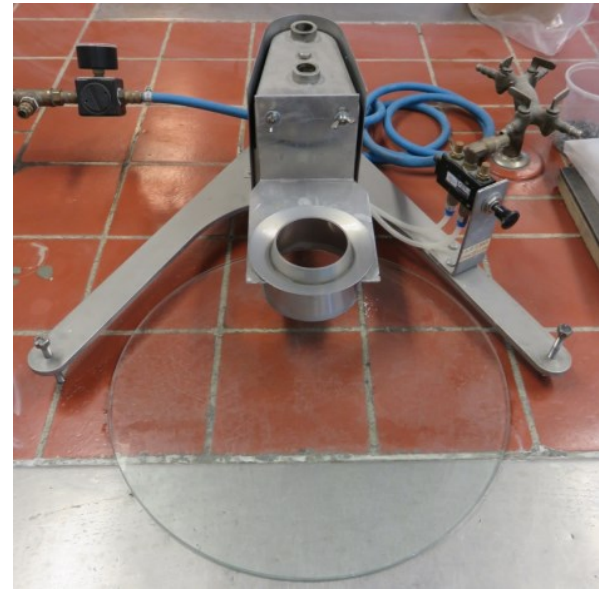

Fig. 1. Pneumatic lifting device for determine the slump flow of the pastes

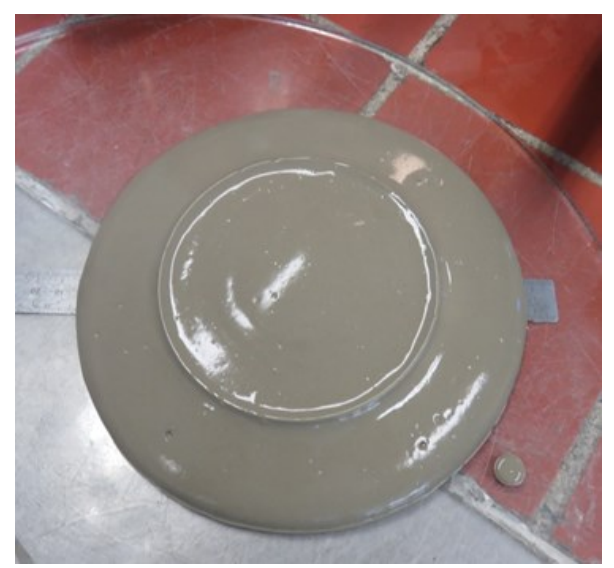

Fig. 2. Determination of the slump flow of a cement paste sample

In the concrete investigations it was obviously, that the unmodified references showed significant appearances of segregation and separation (figure 5) in part. The stabilizing effect of the polymers is well illustrated in figure 6 .

Another aspect of the investigations was the influences of the design concept or rather type of SCC (filler-type, viscosity agent-type and combined-type) on the rheological behavior of the fresh concrete, the hardened concrete properties and the appearance of the concrete surface. It was determined that it is possible to produce functioning self-compacting concretes independent of the type of SCC. The composition of the concretes is shown in Table 1 . In every case the fresh concrete properties were improved due to the polymer modification (table 2). The hardened concrete properties are shown in table 3 .

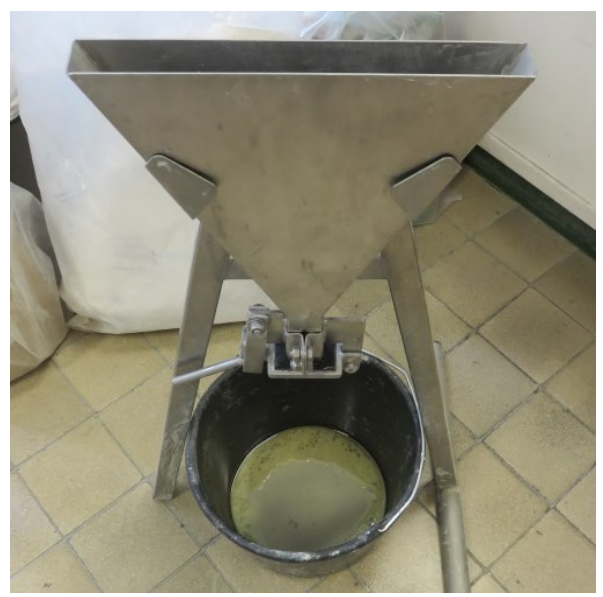

Fig. 3. Determination of the V-funnel flow time of the mortars

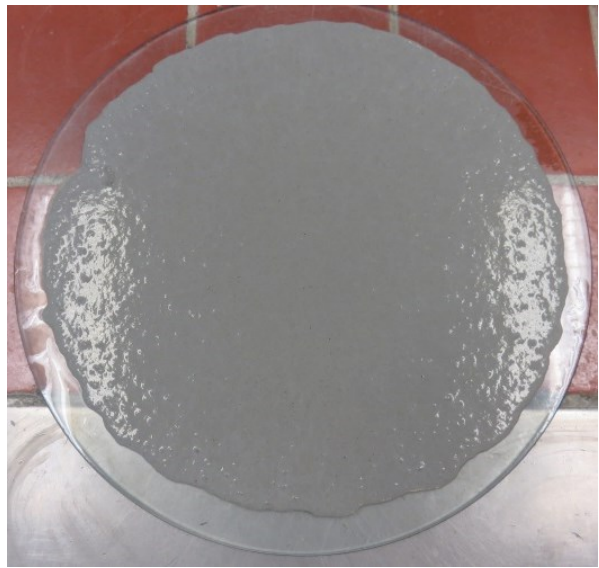

Fig. 4. Determination of the slump flow of the mortars

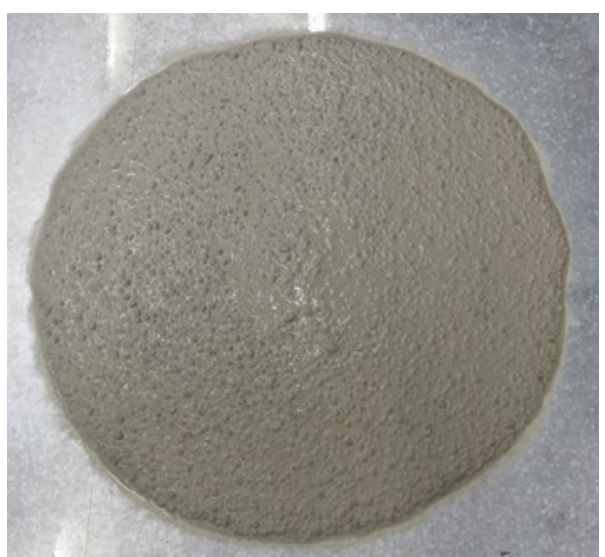

Fig. 5. Unmodified reference (SCC) with appearance of separation 


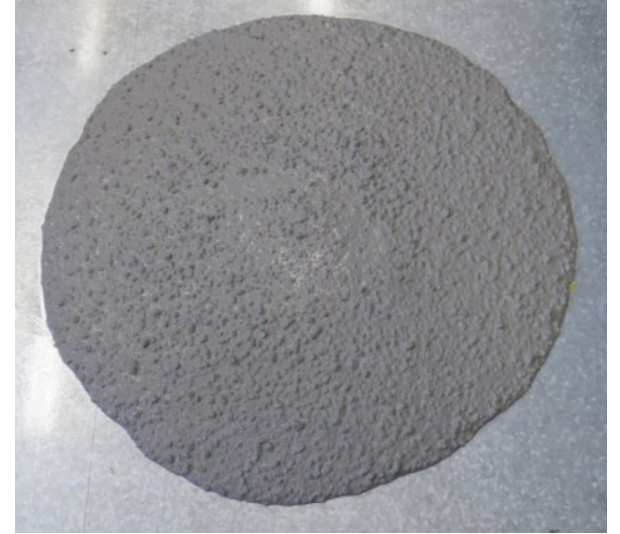

Fig. 6. PSCC with no appearance of separation

For the assessment of the concrete surfaces, samples were produced in special ashlar-formed formworks with a height of $50 \mathrm{~cm}$, a width of $25 \mathrm{~cm}$ and a depth of $3 \mathrm{~cm}$. The surfaces of the formworks have been prepared on the one side with a PE-foil and on the other side with a suitable release agent. Table 4 summarizes the qualities of the surfaces of the different SCC-types. With all variants the polymer-modified SCC revealed a better surface quality. Especially the amount of near-surface air voids is significantly reduced.

Table 1. Composition of the different SCC-Types in $\mathrm{kg} / \mathrm{m}^{3}$

Cem. Limest. Water Polym. PCE VA Aggr.

\begin{tabular}{lcccccccc}
\hline $\begin{array}{l}\text { Filler- } \\
\text { SCC }\end{array}$ & 390 & 260 & 197 & - & 8,8 & - & 1470 \\
$\begin{array}{l}\text { Filler- } \\
\text { PSCC }\end{array}$ & 368 & 245 & 209 & 36,8 & 4,0 & - & 1410 \\
$\begin{array}{l}\text { VA- } \\
\text { SCC }\end{array}$ & 255 & 170 & 186 & - & 12,4 & 3,0 & 1680 \\
$\begin{array}{l}\text { VA- } \\
\text { PSCC }\end{array}$ & 255 & 170 & 208 & 25,5 & 3,3 & 1,8 & 1620 \\
$\begin{array}{l}\text { Comb.- } \\
\text { SCC }\end{array}$ & 330 & 220 & 202 & - & 6,0 & 1,8 & 1540 \\
$\begin{array}{l}\text { Comb.- } \\
\text { PSCC }\end{array}$ & 330 & 220 & 214 & 33 & 6,0 & 1,5 & 1490 \\
\hline
\end{tabular}

\section{Tamped concrete}

Motivated by cooperation partners from practice, a further special concrete with certain properties was included in the investigations. It has been regarded as necessary to introduce the tamped concrete with its particular look and surface structure, because this material was used for many historical and in part heritage concrete buildings of the late 19th and early 20th century. Therefore, it was necessary to develop and customize material, methods and technologies for the restoration of structures made of tamped concrete.

First experiments have been done for the determination of compositions, adjustment and optimization of properties, to the design possibilities and how the properties of the concrete can be influenced by using polymers.

Table 2. Fresh concrete properties of the different SCC-Types

\begin{tabular}{|c|c|c|c|c|c|}
\hline & $\begin{array}{c}\text { Slump- } \\
\text { flow } \\
{[\mathrm{cm}]}\end{array}$ & $\begin{array}{c}\text { V-funnel } \\
\text { flow time } \\
{[\mathrm{s}]}\end{array}$ & $\begin{array}{c}\text { Air void } \\
\text { content } \\
{[\%]}\end{array}$ & $\begin{array}{c}\text { Bulk } \\
\text { density } \\
{\left[\mathrm{g} / \mathrm{cm}^{3}\right]}\end{array}$ & $\begin{array}{c}\text { Tempe- } \\
\text { rature } \\
{\left[{ }^{\circ} \mathrm{C}\right]}\end{array}$ \\
\hline $\begin{array}{l}\text { Filler- } \\
\text { SCC }\end{array}$ & 390 & 260 & 197 & - & 8,8 \\
\hline $\begin{array}{l}\text { Filler- } \\
\text { PSCC }\end{array}$ & 368 & 245 & 209 & 36,8 & 4,0 \\
\hline $\begin{array}{l}\text { VA- } \\
\text { SCC }\end{array}$ & 255 & 170 & 186 & - & 12,4 \\
\hline $\begin{array}{l}\text { VA- } \\
\text { PSCC }\end{array}$ & 255 & 170 & 208 & 25,5 & 3,3 \\
\hline $\begin{array}{l}\text { Comb.- } \\
\text { SCC }\end{array}$ & 330 & 220 & 202 & - & 6,0 \\
\hline $\begin{array}{l}\text { Comb.- } \\
\text { PSCC }\end{array}$ & 330 & 220 & 214 & 33 & 6,0 \\
\hline
\end{tabular}

Table 3. Hardened concrete properties of the different SCC-Types

\begin{tabular}{lcc}
\hline & $\begin{array}{c}\text { Compressive strength } \\
{\left[\mathrm{N} / \mathrm{mm}^{2}\right]}\end{array}$ & $\begin{array}{c}\text { Bulk density } \\
{\left[\mathrm{g} / \mathrm{cm}^{3}\right]}\end{array}$ \\
\hline Filler-SCC & 53,2 & 2,34 \\
Filler-PSCC & 44,4 & 2,28 \\
VA-SCC & 33,4 & 2,30 \\
VA-PSCC & 27,7 & 2,22 \\
Comb.-SCC & 42,9 & 2,33 \\
Comb.-PSCC & 39,5 & 2,24 \\
\hline
\end{tabular}

At the moment the investigations are limited to the determination and adjustment of the concrete composition for a purposeful achievement of the required fresh concrete behaviour and adaption of certain optical properties of the hardened concrete. Beside the adjustment of the composition to reach the optical properties, different manufacturing techniques were tested. In principle, tamped concretes could be produced which correspond in structure (figure 7) as well as in colour to historical tamped concretes (figure 8). The investigations of the durability and the influence of polymers in the structure of the tamped concrete are still in progress. 
Table 4. Surfaces of he different SCC-Types

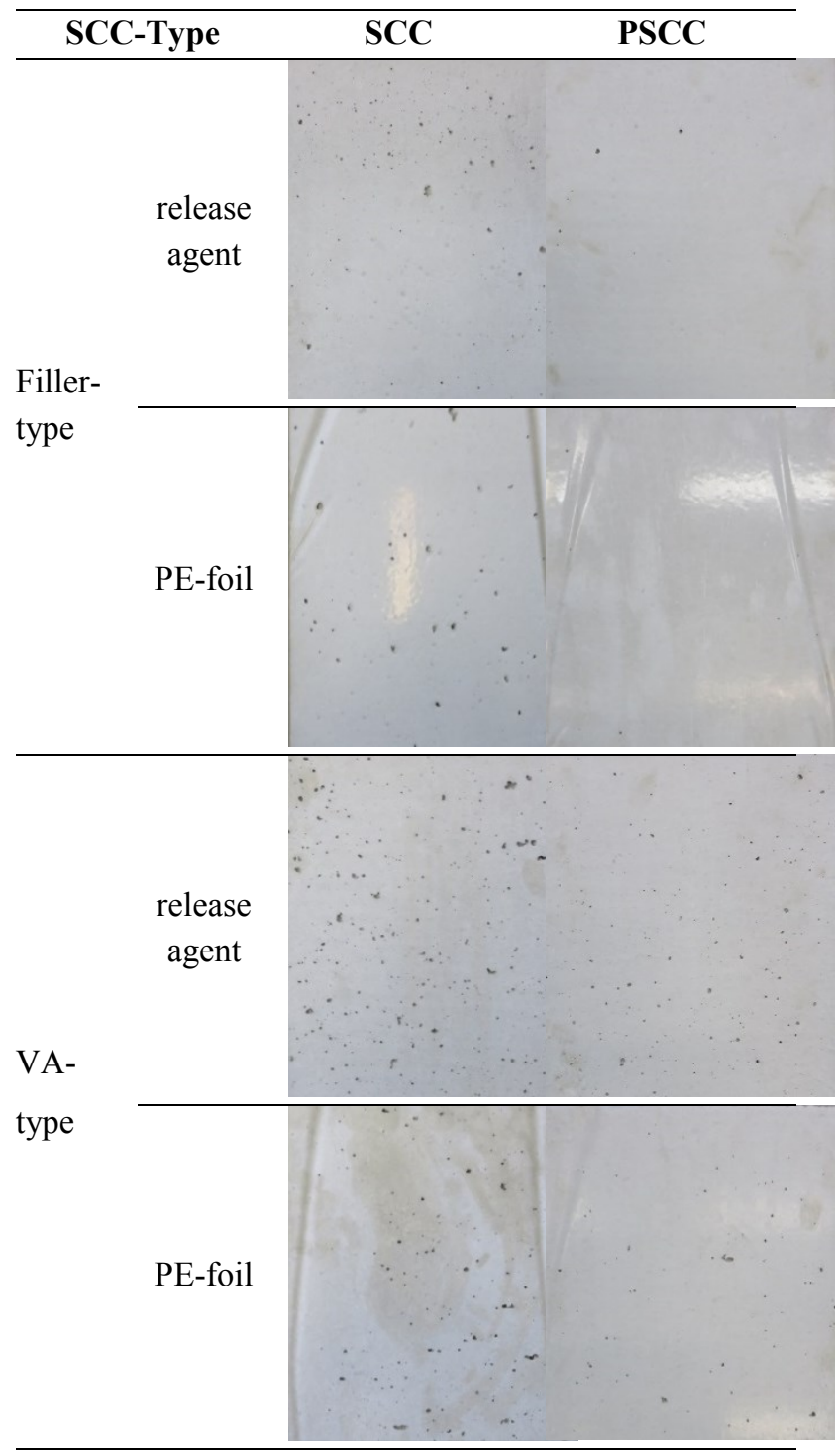

\section{Polymer-modified Supersulphated Cement Concrete (PSSCC)}

Also motivated by cooperation partners from practice, a second special concrete with certain properties the supersulphated cement concrete (SSCC) was included in the investigations. Goal of the investigation was to clarify if the polymer-modification of SSCC leads to similar benefits as known from polymer-modified Portland cement concrete (PCC). It became apparent that important properties which are relevant for the durability of the concrete could be improved due to the polymermodification, but there are also differences to the characteristics of PCC. The Compositions of the SSCC and the PSSCC is specified in table 5.

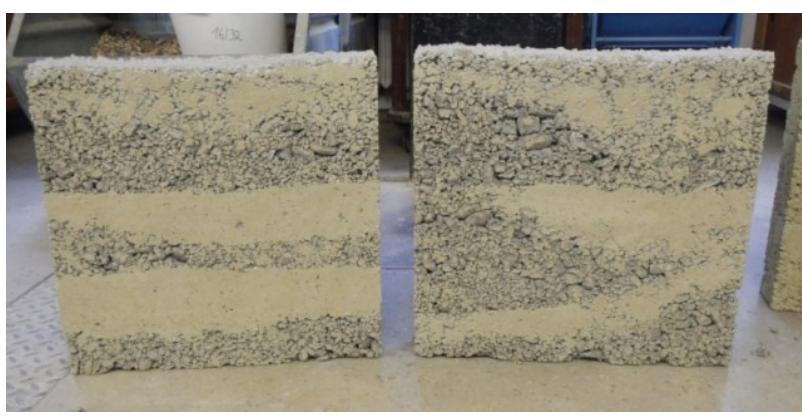

Fig. 7. Structural design of tamped concrete

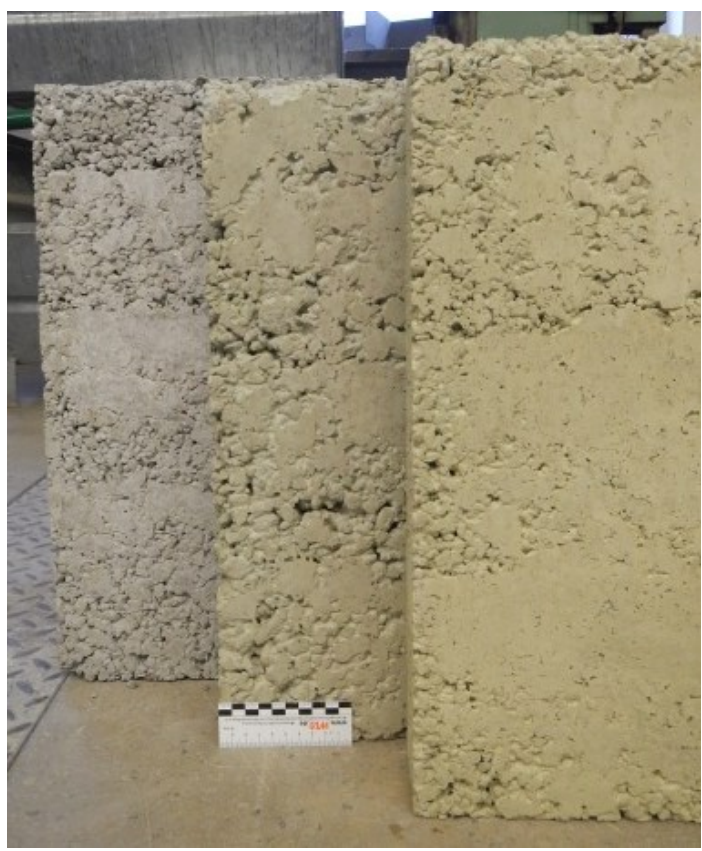

Fig. 8. Colour design of tamped concrete

Table 5. Compositions of the super-sulphated cement concretes in $\mathrm{kg} / \mathrm{m}^{3}$

\begin{tabular}{lcc}
\hline & SSCC & PSSCC \\
\cline { 2 - 3 } Super-sulphated cement & 340 & 340 \\
Water & 187 & 187 \\
Polymer & - & 34 \\
Aggregates & 1800 & 1720 \\
\hline
\end{tabular}

The processability of the fresh SSCC (table 6) could be improved through the addition of the polymers. A superplasticizing effect and simultaneous no separation, no sedimentation and no segregation were observable.

The properties of the hardened concrete displayed some variations from the known properties of PCC. The increased bending tensile strength and the decreased Young's-modulus are important benefits for reconstruction materials and known from conventional PCC. The increased compressive strength of the polymer-modified SSCC was not expect-able (figure 9, 10 and 11). The reasons for this increase in compressive strength are investigated in further analyses. 
Table 6. Fresh concrete properties of the different SCC-Types

\begin{tabular}{lcccc}
\hline & $\begin{array}{c}\text { Flow } \\
\text { spread } \\
{[\mathrm{mm}]}\end{array}$ & $\begin{array}{c}\text { Air void } \\
\text { content } \\
{[\%]}\end{array}$ & $\begin{array}{c}\text { Bulk } \\
\text { density } \\
{\left[\mathrm{g} / \mathrm{cm}^{3}\right]}\end{array}$ & $\begin{array}{c}\text { Tempe- } \\
\text { rature } \\
{\left[{ }^{\circ} \mathrm{C}\right]}\end{array}$ \\
\hline SSCC & 420 & 1,9 & 2,31 & 20,6 \\
PSSCC & $<630$ & 1,6 & 2,29 & 19,6 \\
\hline
\end{tabular}

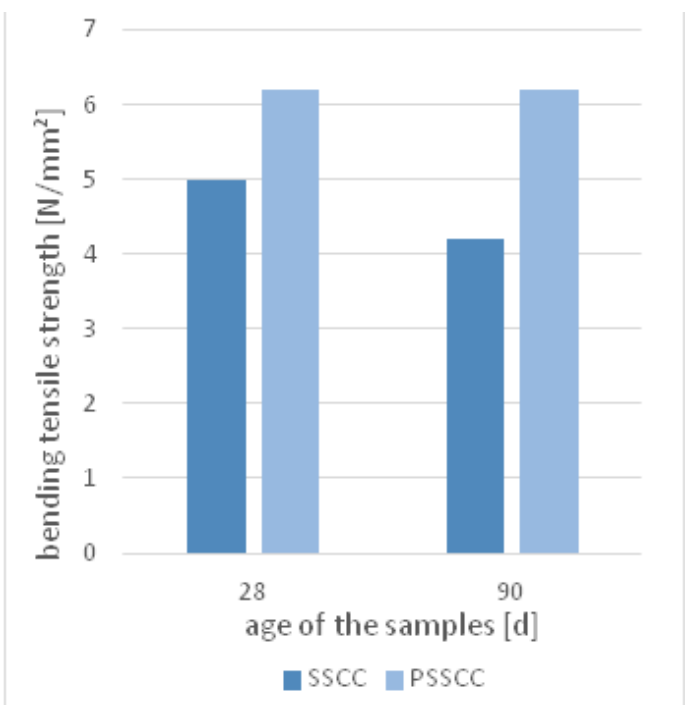

Fig. 9. Bending tensile strength of the samples

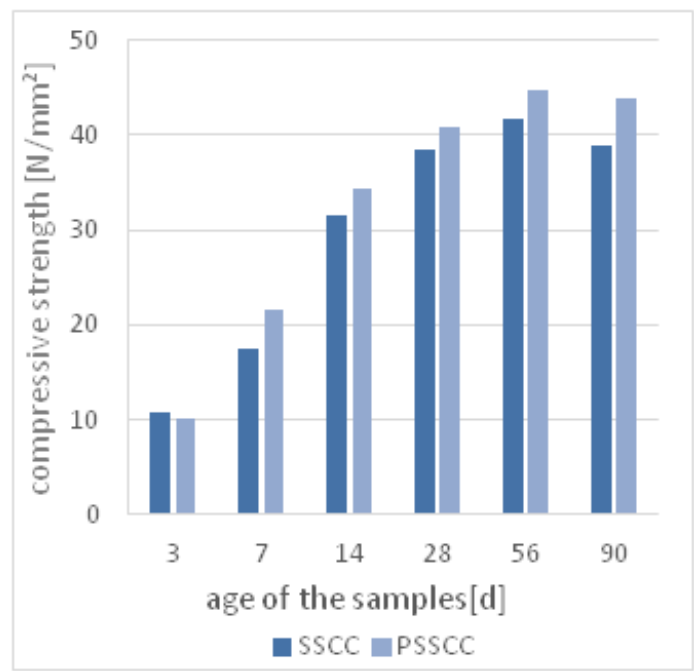

Fig. 10. Compressive strength of the samples

Considering the microstructure of the concretes, it is observable that the pore radius distribution of the PSSCC shifts towards smaller pore radii. A significant decrease of pores with capillary effect was visible (figure 12). The decreased part of capillary pores has a positive effect on the durability of the material. Furthermore, a significant decrease of depth of carbonation was determined. That is evidence for a denser structure and therewith for a higher resistance against media which cause corrosion. Further investigations to the influence of the water-cement-ratio and the polymer-cement-ratio are still in progress.

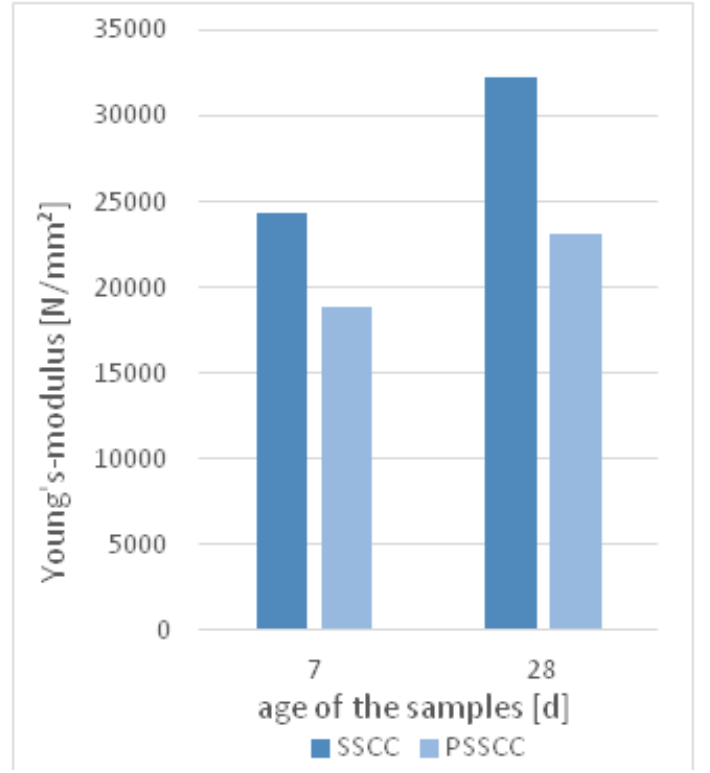

Fig. 11. Young's-modulus of the samples

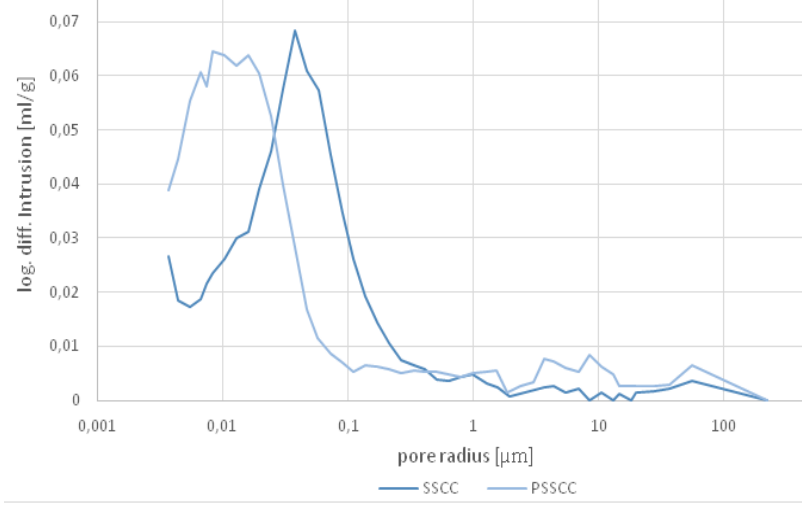

Fig. 12. Pore radius distribution of the polymer-modified concrete and the reference concretes determined with mercury intrusion porosimetry

Based on scanning electron microscope images of the binder of the concretes, considerable morphologic differences of the crystalline structures of the PSSCC and the reference were visible (figure 13 and 14). The hypothesis is that the formation of ettringite is restrained due to the polymer-modification and the prismatic crystals formed are smaller in shape.

Furthermore, was observable, that the adsorption process and the film formation of the polymers are completed after $48 \mathrm{~h}$. The polymers are homogeneous distributed in the cement phase of the concretes. 


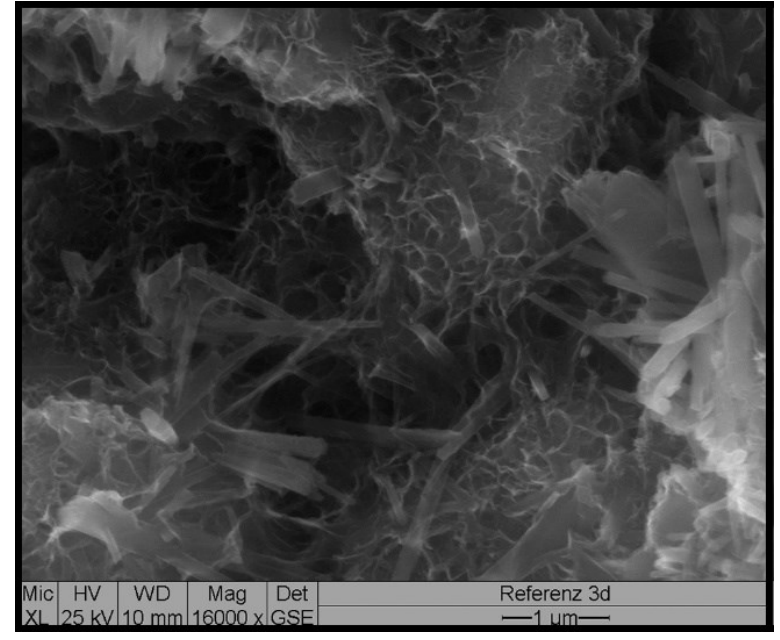

Fig. 13. SEM-images of SSCC after $72 \mathrm{~h}$ of hydration

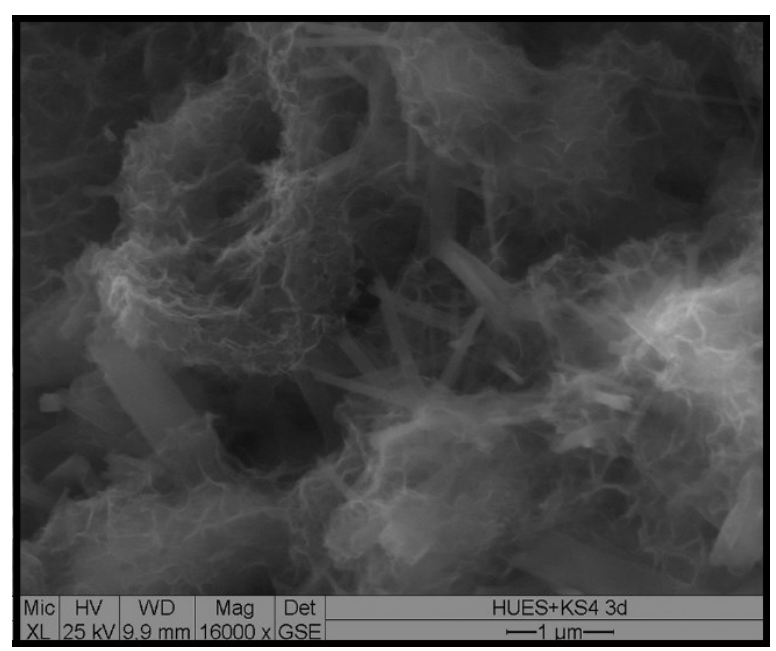

Fig. 14. SEM-images of PSSCC after $72 \mathrm{~h}$ of hydration

\section{Conclusions}

Finally, it can be stated that every single rehabilitation task of historical concrete structures needs a specific analysis of the state of construction and therewith a certain selection of the reconstruction material. For a purposeful adjustment of the reconstruction material on the original substance usually specific investigations or even innovative material developments are necessary. In many cases the modification of the cementitious reconstruction material with polymers is useful to ensure its durability and to adapt mechanical properties. Furthermore, PSCC and PSSCC for repair of monuments can be made, with similar surface aspect and improved rheological and durability properties.

The presented studies are part of the research project "Methods for the development and application of innovative, functional materials for the restoration of buildings". It is funded by the Federal Ministry of Education and Research, Germany and belongs to the initiative "Innoprofile".

\section{References}

1. H.A. Heinemann, Historic Concrete: From Concrete Repair to Concrete Conservation, doctoral thesis, ISBN 9789052694115 (2013)

2. H. Okamura, M. Ouchi, Self-Compacting Concrete. Journal of Advanced Concrete Technology, Nr. 4 p. 5-15 (2003)

3. Y. Ohama, T. Moriwaki, K. Shiroisshida, Weatherability of polymer-modified mortars through ten-year outdoor exposure, in proceedings of IV. ICPIC, p. 67-71 (1984)

4. A. Gypser, A. Flohr, A. Osburg, Advanced Materials Research, Vol. 1129, p.557 - 564, (2015)

5. A. Gypser, A. Flohr, A. Osburg, Bulletin of Materials Research and Engineering, p. 349-357 (2017)

6. A. Hummel, K. Charisius, Baustoffprüfungen 3 (1957)

7. G. Amthor, BAW-Brief Nr. 6 - Empfehlungen zu Untersuchungen und Instandsetzung Thuramentund sulfathüttenzementhaltiger Betone (2012) 